\title{
Location of extra-adrenal catecholamine secreting tumours by selective venous sampling and nuclear magnetic resonance scanning
}

\author{
J.R. Cockcroft ${ }^{1}$, J.M. Ritter ${ }^{1}$, D.J. Allison ${ }^{2}$, R. Causon' ${ }^{1}$ and M.J. Brown ${ }^{3}$ \\ ${ }^{1}$ Department of Clinical Pharmacology, Royal Postgraduate Medical School, Hammersmith Hospital, Ducane \\ Road, London W120HS, '2 Department of Diagnostic Radiology, Hammersmith Hospital, Ducane Road, London \\ W12 OHS and ${ }^{3}$ Clinical Pharmacology Unit, Level 2, F \& G Block, Addenbrooke's Hospital, Hills Road, \\ Cambridge CB2 2QQ, UK.
}

\begin{abstract}
Summary: Iodinated meta-iodobenzylguanidine (MIBG) scanning is a safe non-invasive method for locating extra-adrenal paragangliomas. However, a positive result is dependent on the presence of an uptake mechanism in the tumour. We report two cases of MIBG negative intracranial catecholamine secreting tumours successfully located by selective venous sampling and nuclear magnetic resonance scanning.
\end{abstract}

\section{Introduction}

Selective venous sampling accurately identifies phaeochromocytoma in the difficult sub-group of patients without an adrenal mass on computed tomography (CT). ${ }^{1}$ Meta-iodobenzylguanidine (MIBG) scanning is also valuable in this situation, ${ }^{2}$ where it is the investigation of first choice since it is non-invasive. False negative MIBG scans do occur however. ${ }^{2}$ We report two such cases: one, a tumour of the glomus jugulare, and one, the first described instance of a catecholamine secreting paraganglioma in the pterygopalatine fossa. In each, MIBG scanning was negative while selective venous sampling successfully located the tumours, which were further defined by nuclear magnetic resonance scanning (NMR).

\section{Case reports}

Case 1

A 40 year old man had a blood pressure of 260 / $140 \mathrm{~mm} \mathrm{Hg}$. Urinary vanillyl mandelic acid (VMA) was raised $(56 \mu \mathrm{mol} / 24 \mathrm{~h}$; normal range $<10-35)$. Plasma noradrenaline was elevated $(5.4 \mathrm{ng} / \mathrm{ml}$; normal range $0.2-0.8$ ). Plasma adrenaline and abdominal CT scanning were normal. MIBG scanning of head, thorax and abdomen was negative. Selective venous

Correspondence: J.R. Cockcroft, B.Sc., M.R.C.P.

Accepted: 16 December 1986 sampling demonstrated high concentrations of noradrenaline in both internal jugular veins (Figure 1a). A partial saturation (PS 300/22) scan showed a tumour in the region of the jugular bulb (Figure 1b). Angiography showed that this was supplied by the left vertebral and left external carotid arteries. It was embolized (Dr B. Kendall) and partially removed (Professor L. Symon). The patient underwent radiotherapy and is normotensive on labetalol. Histologically the tumour was a chemodectoma.

\section{Case 2}

A 35 year old woman gave a 2 year history of hot flushes, headaches and palpitations. Her blood pressure was $215 / 140 \mathrm{~mm} \mathrm{Hg}$. Urinary VMA was $123 \mu \mathrm{mol} / 24 \mathrm{~h}$. Plasma noradrenaline was $6.5 \mathrm{ng} / \mathrm{ml}$. Plasma adrenaline was normal, as was CT scanning of abdomen and thorax. MIBG scanning of head, thorax and abdomen was negative. Selective venous sampling (Figure 1c) demonstrated high concentrations of noradrenaline in the left external jugular vein. A spin-echo (SE 544/44) scan showed a tumour in the left pterygo-palatine fossa, extending into the posterior maxillary sinus (Figure 1d). Arteriography showed that the major blood supply was a branch of the maxillary artery. The tumour was embolized and removed completely (Mr A.D. Cheesman). The patient is now normotensive without medication. Histologically the tumour was a paraganglioma. 
a
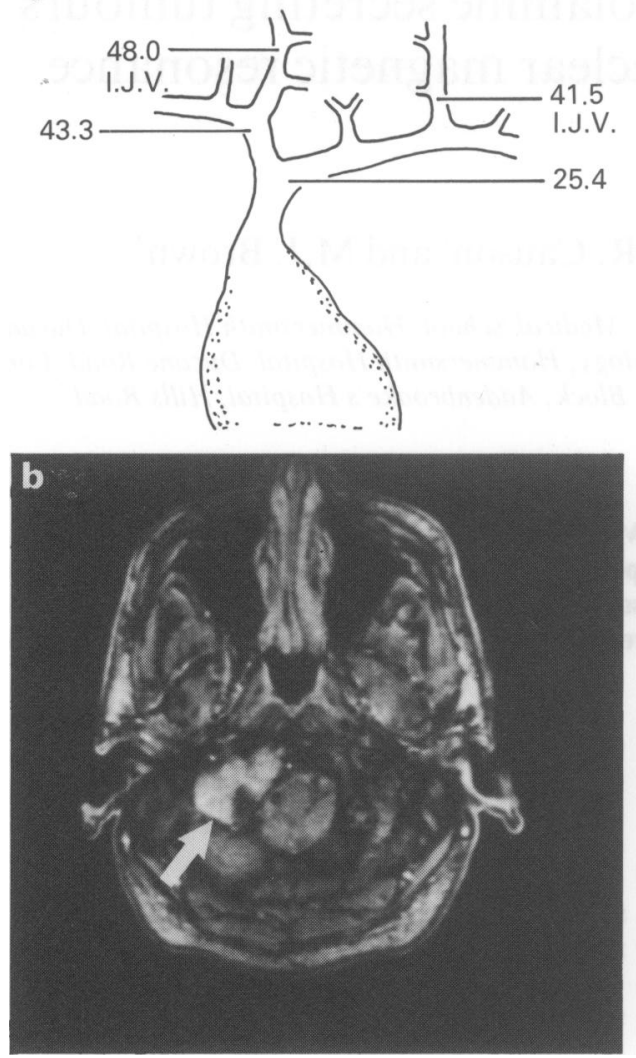

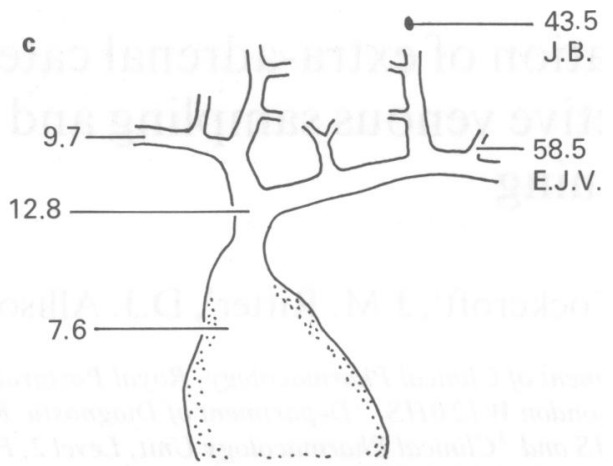

d

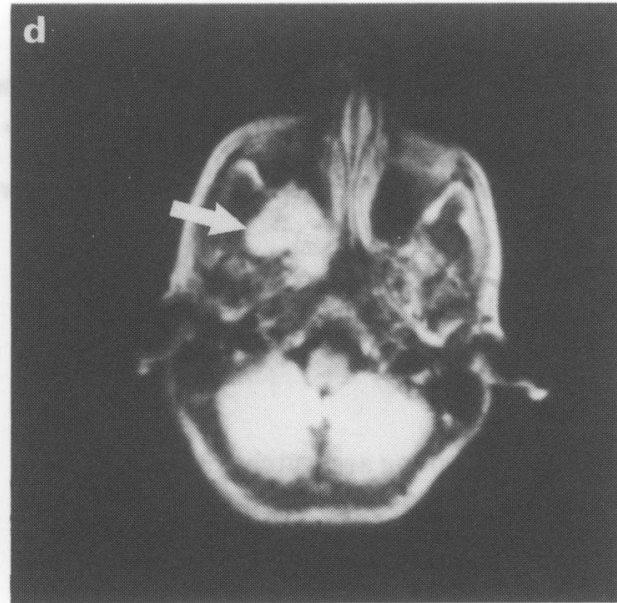

Figure 1 Regional venous noradrenaline concentrations (ng/ml) and NMR scans from two patients with intracranial phaeochromocytoma. In one, noradrenaline concentrations (a) were markedly raised in both internal jugular veins (I.J.V) compared to the arterial concentration $(9.5 \mathrm{ng} / \mathrm{ml})$. The PS $300 / 22$ scan (b) showed a tumour in the jugular foramen (arrow) with compression of the cerebellum and distortion of the brainstem. In the second patient noradrenaline concentrations (c) were most elevated in the left jugular bulb (J.B.) and external jugular vein (E.J.V.) compared with the arterial concentration $(10.3 \mathrm{ng} / \mathrm{ml})$. The corresponding SE $544 / 44$ scan (d) showed a tumour (arrow) in the left ptyergo-palatine fossa.

\section{Discussion}

Urinary VMA is a useful screening test for phaeochromocytoma. Most adrenal tumours are associated with elevated plasma adrenaline concentrations, and can be located by CT scanning.' Extra-adrenal tumours often secrete noradrenaline rather than adrenaline, as in our cases, and are more difficult to localize. MIBG scanning is therefore the most valuable non-invasive technique when the plasma noradrenaline is elevated but the adrenaline concentration is normal. $^{2}$ However, MIBG scanning can only be positive if an uptake mechanism is present. The processes of amine uptake and secretion are sometimes dissociated, as in the glomus jugulare tumour and pterygo-palatine fossa paraganglioma described. The latter tumour is thought to arise from a fetal remnant of paraganglionic tissue surrounding the maxillary artery, ${ }^{3}$ which supplied the tumour in our case. Thirteen cases have been described previously, ${ }^{4}$ but none that has been secretory. The present cases indicated the importance of selective venous sampling in MIBG negative catecholamine secreting extraadrenal tumours. The partial saturation sequence used in the first case results in cancellation of the signal from red marrow at the base of the skull, highlighting 
the tumour. The spin-echo sequence SE 544/44 displays moderate $T_{1}$ dependence. In neither case did the tumour display the low signal areas described by Olsen et al. in 12 cases of paragangliomas greater than $2 \mathrm{~cm}$ in diameter. ${ }^{5}$ This may have been a consequence of the relatively short echo time values used in these cases $(22$ and $44 \mathrm{~ms}$ ) which did not cause sufficient dephasing of the blood signal to produce a signal void.

\section{References}

1. Allison, D.J., Brown, M.J., Jones, D.H. \& Timmis, J.B. Role of venous sampling in locating phaeochromocytoma. Br Med J 1983, 286: 1122-1124.

2. Shapiro, B., Copp, J.E., Sisson, J.C., Eyre, P.L., Wallis, J. \& Beierwalter, W.H. Iodine-131 metaiodobenzylguanidine for the locating of suspected phaeochromocytoma: Experience in 400 cases. $\mathrm{J} \mathrm{Nucl} \mathrm{Med}$ 1985, 26: 576-585.

3. Girgis, I.H., Fahmy, S.A. Nasopharyngeal fibroma: Its

\section{Acknowledgements}

We would like to thank the NMR Unit at Hammersmith Hospital for their assistance in performing the scans of both patients. Embolization and surgery were performed at the National Hospital for Nervous Diseases, Queen Square, London WC1.

histo-pathological nature. J Laryngol Otol 1973, 87: 1107-1123.

4. Scoppa, J. \& Tonkin, J.P. Non-chromaffin paraganglioma of the nasopharynx. J Laryngol Otol 1974, 88: $653-656$.

5. Olsen, W.L., Dillon, W.P., Kelly, W.M., Norman, D., Brant-Zawodski, M. \& Newton, T.H. MR imaging of paragangliomas. AJNR 1986, 7: 1039-1042. 